\title{
The Moderating Role of Business Intelligence in the Impact of Big Data on Financial Reports Quality in Jordanian Telecom Companies
}

\author{
Omar Mohammed Zraqat ${ }^{1}$ \\ ${ }^{1}$ Faculty of Business \& Finance, The World Islamic Sciences \& Education University (W.I.S.E), Amman, \\ Jordan. \\ Correspondence: Omar Mohammed Zraqat, Faculty of Business \& Finance, The World Islamic Sciences \& \\ Education University (W.I.S.E), Amman, Jordan.
}

Received: January 7, 2020

Accepted: January 28, 2020

Online Published: January 29, 2020

doi:10.5539/mas.v14n2p71

URL: https://doi.org/10.5539/mas.v14n2p71

\begin{abstract}
This study aimed at discovering the impact of big data in terms of its dimensions (Variety, Velocity, Volume, and Veracity) on financial reports quality in the present business intelligence in terms of its dimensions (Online Analytical Processing (OLAP), Data Mining, and Data Warehouse) as a moderating variable in Jordanian telecom companies. The sample included (139) employees in Jordanian Telecom Companies. Multiple and Stepwise Linear Regression were used to test the effect of the independent variable on the dependent variable. And Hierarchical Regression analysis, to test the effect of the independent variable on the dependent variable in the presence of the moderating variable.

The study reached a set of results, the most prominent of which was the presence of a statistically significant effect of using big data in improve the quality of financial reports, Business intelligence contributes to improving the impact of big data in terms of its dimensions (Volume, Velocity, Variety, and Veracity) on the quality of financial reports. The study recommends the necessity of working on making use of big data and resorting to business intelligence solutions because of its great role in improving the quality of financial reports and thus supporting decision-making functions for a large group of users.
\end{abstract}

Keywords: big data, financial reports quality, business intelligence, Jordanian Telecom Companies

\section{Study Background}

\subsection{Introduction}

Economic globalization began in the nineties in advancing global competition, which led to the creation of a new business environment that requires organizations to be more responsive to the problems and opportunities available so that companies can adapt to them, which led to an increase in information value and the need for it by all relevant parties (Wesna, 2013). Electronic technology and computers have led to the phenomenon of data explosion (Zadeh et al., 2015), This has been accompanied by an increase in data collection and analysis at a great rate, as data mining and analysis is the second most important technology after mobile technology (Rouhani et al., 2016). This is due to the high value of data analytics, as companies already use insights from newly available data sources to define their strategy. and given that accounting is an information system that determines economic events for institutions and records and reveals this information to decision-makers (Davenport, 2014). Accounting had to keep pace with these developments by adapting to the large volume of data.

More recently, big data has become a term widely used to describe big data sets that require advanced data management techniques (Varma, 2018). The big volume, high velocity, and wide variety and veracity of features separate big data from "traditional" data (Chen et al., 2012). Big data and advanced analyzes of it have been widely discussed in IT literature, however, this phenomenon has not received sufficient attention among the academic circles of financial accounting and its role in financial reporting has not been addressed, given that big data has the potential to change financial accounting and reporting practices by providing more information at the right time at a faster rate.

In order to activate the role of big data in financial reporting, it was necessary to pay attention to Business Intelligence as a data-centered approach, as business intelligence and its analyzes have roots in the field of data 
management; it is a way to facilitate the collection of data from a variety of sources and then extract and analyze them, and business intelligence has emerged as an Important field of study because data-related problems and its tools and applications are the basis for any technology to support decisions (Chauke, 2018).

this study came in an attempt to discover the potential impact of big data on financial reports quality in the presence of business intelligence as a moderating variable.

\subsection{Motivation}

Use of big data and big data analytics has increased recently in business, and growth is expected to continue accelerating, but the application of big data in accounting is still at an early stage, although the emergence of big data and data analytics is expected to create an opportunity for accountants and auditors to develop their skills (Alles, 2015). Financial reporting users also need to raise awareness of different types of knowledge, the challenges in creating and applying that knowledge and be more careful about what can be achieved through advances in information-based technologies and programs. In addition, changes in financial reports are affected by developments in how data, information, and knowledge are used, and therefore the study of the effects of big data and business intelligence and their role in the quality of financial reporting is considered beneficial to all interested in accounting information.

\subsection{Study Problem}

There is a growing awareness of the importance of an effective information system to provide accurate and timely information to serve users' needs of accounting information, and one of the main problems facing organizations today is the problem of the huge volume of data that passes to it and the multiplicity of its sources and forms. And since the organizations in the telecommunications and technology sector are exposed to more data, perhaps more than others, the decisions should not be based on instinctive or random events but rather be clear, understandable, correct and ready to be presented in a way that adds value to users, hence the great need for business intelligence and its application to improve the quality Financial reporting, by making effective decisions based on a continuous flow of quality information that is constantly updated, as its primary business intelligence function is to transform data into more easily interpretable information. Consequently, the study problem can be expressed in the following questions:

1. Is there an impact of big data in terms of its dimensions (Volume, Velocity, Variety, and Veracity) on financial reports quality in Jordanian Telecom Companies?

2. Is there an impact of business intelligence in terms of its dimensions (Online Analytical Processing (OLAP), Data Mining, Data Warehouse) on financial reports quality in Jordanian Telecom Companies?

3. Is there an impact of big data in terms of its dimensions (Volume, Velocity, Variety, and Veracity) on financial reports quality in presence business intelligence as a moderating variable in Jordanian Telecom Companies?

\subsection{Study Objectives}

The purpose of this study is to enrich accounting literature in general, and financial accounting in particular from academic research related to big data and business intelligence, and to highlight areas for further research in accounting and finance. More specifically, this study seeks to explore the potential impact of big data in terms of its dimensions (Volume, Velocity, Variety, and Veracity) on financial reports quality in the presence of business intelligence as a moderating variable.

\section{Literature Review}

According to a resource-based perspective theory, an organization is a collection of resources and provides a powerful framework for consolidating many different resources that can be combined to generate benefits for the organization (Gupta \& George, 2016). Data and capabilities can be understood as subsets of these resources that are not imitation or transferable, have a direct or indirect impact on the company's performance, and are affected by environmental conditions (Gunasekaran et al., 2017). Given the context of our study, the theory of resource-based perspective is important to achieving its goals, because knowing what are the resources for big data that the company has and creating an appropriate way to use it is the key to achieving excellence in relation to financial reporting. Moreover, researchers in management disciplines emphasize that a resource-based perspective theory has the capacity to accommodate different streams of research and theories in order to create a comprehensive strategic theory of the organization (Palmatier et al., 2007; Peteraf, 1993; Mahoney \& Pandian, 1992). In addition to the resource-based perspective theory, the theories "knowledge-based view" and "dynamic capabilities" as extensions of the resource-based perspective theory have gained attention from IT strategy 
literature (Barney, et al., 2011). In a comparative study (Schüll \& Maslan, 2018), they found that resource-based perspective theory is almost the most used theory when studying the impact of information technology, and (Ghasemaghaei, 2018) reached the same conclusion in studying the impact of big data.

The fourth industrial revolution, Industry 4.0, points to new digital industrial technology, digital transformation, and the fourth stage of technological advancement that fosters all aspects of the business. Cyber-Physical Systems (CPS) and the Internet of Things (IoT) are the most important forces of Industry 4.0 that operate to improve business processes through groundbreaking innovations. Industry 4.0 with integrated production and logistics operations and the increasing interaction between robots and human and data flows within global value chains will have a major impact on all businesses. In this context, the accounting profession, which has a very important job for companies, needs to adapt to Industry 4.0 because it provides a new ability to transform the accounting process by digitizing and applying new tools to Sector 4.0 such as big data analytics, networks, and system integration (Aslanertik \& Yardımc1, 2019).

In this context, it must be noted that institutions need to be aware of the different types of knowledge, and the challenges facing the creation and application of this knowledge (Bhimani \& Willcocks, 2014), and the capabilities of large data presented in relation to the financial reporting function should be identified, as "technologies Big Data "and data analysis may provide an opportunity to collect a wide range of data and analyze it in a way that improves the quality of financial report (George et al., 2019). As the use of big data and business intelligence techniques allows users to access information from any mobile device, regardless of the geographical location and time of day, which contributes to improving the ability of the financial statement preparers and increases its contribution to decision-making (Kamordzhanova \& Selezneva, 2019).

\section{Big Data, Business Intelligence and Quality of Financial Reports}

Big data definitions possess many nuances and varied meanings (De Mauro et al 2015). Therefore, the first step in reviewing the literature and analyzing its potential impacts on the quality of financial reporting is to define the term. Watson (2014) believes that the name "big data" is given to the data because of its size, the speed at which it reaches it, and the variety of shapes it takes. Davis (2014) believes that big data consists of massive data sets (large volumes) that are updated quickly and repeatedly (high speed) which displays a large collection of different shapes and contents (wide variety). Abbasi et al. (2016) argues that big data differs from 'normal' four-dimensional data, or '4 Vs' - its Volume, Velocity, Variety, and Veracity.

In general, big data can be viewed and its relationship to the quality of financial reports through the four dimensions '4 Vs' (Volume, Velocity, Variety, and Veracity). As the variety of data sources lends more credibility to this data, which is reflected in the quality of the information contained in financial reports and enables companies to increase the disclosures they provide, and here highlights the role of business intelligence techniques in processing these data to produce them in an organized and understandable way.

With regard to velocity, it means the rate of growth and production of data or the speed of data extraction, which is the time that we take from the moment these data arrive at the moment when the decision is made based on them (De Mauro et al., 2015). Velocity is a critical element in decision-making based on this data, because the "novelty" of data that decision-makers can collect, as well as the ability to analyze these data paths, is an important factor when it comes to improving business speed and enabling actions in real-time and making decisions during the day. The role of business intelligence technologies has emerged with a huge increase in the speed of data frequency, and this is also due to the diversity of its sources. The need has become more urgent to a system that guarantees a high speed in the analysis of big data in real-time or the speed of convergence of the instantaneous time.

As for the volume, the increasing amounts of data that are collected because of its speed and the diversity of its resources available to the organization do not necessarily need to have all of them as long as they can access them, as the variety of data sources has turned small data into big data (Ramesh, 2015), which may have an impact on the quality of financial reports, as it is difficult for companies to deal with huge amounts of data, which requires resorting to business intelligence techniques.

Finally, veracity contributes greatly to improving the quality of financial reports, as the lack of reliability and uncertainty inherent in the information due to late access, inconsistency, and subjectivity in data affect the ability of users to make decisions (McAfee et al., 2012), and therefore veracity is one of the biggest challenges when analyzing big data, And it must be dealt with by correctly identifying the problem during the analysis, finding relevant data and using proven techniques for analysis so that the result is trustworthy (Kumar, 2018). 
Sun et al. (2018) indicated that big data analytics uses data mining to access information from a large data set in order to support decision-making and analyze and improve business processes. Consequently, big data analyzes provide the ability to capture causal and interrelated processes in a real-time basis and financial accounting has significantly changed and inheritance reporting, relying on structured data and successive layers of summary, aggregation, and reporting on a periodic basis (Griffin and Wright, 2015). Warren et al. (2015) confirm that big data can significantly affect the future of financial reports and develop generally accepted accounting principles specifically for reporting off-budget assets and calculating fair value.

Also, business intelligence has a prominent role in the quality of financial reports. Duan and Xu (2012) believes that business intelligence is the process of converting raw data into useful information for more effective strategic and operational visions, and for decision-making purposes in order to achieve real business benefits. This helps in refining the financial reports and contributes to improving their quality. Likewise, Loshin (2013) believes that business intelligence represents technological tools and processes that help convert data into information and knowledge. Balachandran \& Prasad (2017) believe that business intelligence refers to technologies, applications, and practices for collecting, integrating, analyzing, and displaying business information to support better and faster business decisions. This is in line with the objectives of the financial reports to help its users make decisions.

Data management from the point of view of business intelligence includes extracting data from various operating systems within the organization and from other external sources and preparing it to meet the requirements for converting it to information, and therefore it includes data quality, especially in source systems, data quality is important to the business intelligence system when incorporating data from several sources and analyzing them In order to improve the decision-making process (Yeoh \& Koronios, 2010), the quality of data and how it is facts affect the consistency of its representation, its interpretation and how easy it is to understand, otherwise, business intelligence will not be smart (Shollo \& Galliers, 2015). Usually, many issues are not discovered within the back-end systems until the data is loaded into the business intelligence system. Other times, the data may be accurate at the source level, but it cannot be used with other data sources due to the different format. Therefore, it is necessary to have common standards and definitions (standardization) that allow the use of data from different operational circuits (Popovic \& Yeoh, 2016).

\section{Study Hypotheses}

According to the previous literature review, the following hypotheses have been formulated:

The first main hypothesis Ho1: There is no statistically significant effect at the significance level $(\alpha \leq 0.05)$ of the Big Data in terms of its dimensions (Variety, Velocity, Volume, Veracity) on the financial report's quality.

This main hypothesis is divided into the following sub-hypotheses:

Ho1-1: There is no statistically significant effect at the significance level $(\alpha \leq 0.05)$ of data variety on the financial report's quality.

Ho1-2: There is no statistically significant effect at the significance level $(\alpha \leq 0.05)$ of data velocity on the financial report's quality.

Ho1-3: There is no statistically significant effect at the significance level $(\alpha \leq 0.05)$ of data volume on the financial report's quality.

Ho1-4: There is no statistically significant effect at the significance level $(\alpha \leq 0.05)$ of data veracity on the financial report's quality.

The second main hypothesis Ho2: There is no statistically significant effect at the significance level $(\alpha \leq 0.05)$ of business intelligence in terms of its dimensions (Online Analytical Processing (OLAP), Data Mining, and Data Warehouse) on the financial report's quality.

This main hypothesis is divided into the following sub-hypotheses:

Ho2-1: There is no statistically significant effect at the significance level $(\alpha \leq 0.05)$ of online analytical processing (OLAP)on the financial report's quality.

Ho2-1: There is no statistically significant effect at the significance level $(\alpha \leq 0.05)$ of data mining on the financial report's quality.

Ho2-1: There is no statistically significant effect at the significance level $(\alpha \leq 0.05)$ of data warehouse on the financial report's quality. 
The third main hypothesis Ho3: There is no statistically significant effect at the significance level $(\alpha \leq 0.05)$ of the Big Data in terms of its dimensions (Variety, Velocity, Volume, Veracity) on business intelligence.

Ho3-1: There is no statistically significant effect at the significance level $(\alpha \leq 0.05)$ of data variety on the business intelligence.

Ho3-2: There is no statistically significant effect at the significance level $(\alpha \leq 0.05)$ of data velocity on the business intelligence.

Ho3-3: There is no statistically significant effect at the significance level $(\alpha \leq 0.05)$ of data volume on the business intelligence.

Ho3-4: There is no statistically significant effect at the significance level $(\alpha \leq 0.05)$ of data veracity on the business intelligence.

The fourth main hypothesis Ho4: There is no statistically significant effect at the significance level $(\alpha \leq 0.05)$ of the Big Data in terms of its dimensions (Variety, Velocity, Volume, Veracity) on the financial report's quality presence business intelligence as a moderating variable.

\section{Study Methodology}

This study is considered one of the applied researches studies in solving field problems and developing work methods and productivity in the accounting fields. The researcher collects qualitative data that are quantitatively analyzed. The study relied on the descriptive analytical approach to describe the impact of big data on the quality of financial reports in the presence of business intelligence as a moderating variable, by using different statistical methods to analyze the data that were collected through a questionnaire designed to measure the variables of the study model.

\subsection{Population and Sample}

The study population included all employees in Jordan Telecom (Umniah, Orange, and Zain), and they are (3396) employees, (461) employees in Umniah Telecom, (1717) employees in Jordan Telecom (Orange), and (1218) employees At Zain Jordan Telecom. And because of the difficulty and cost of the comprehensive survey, a simple random sample was drawn, based on the Krejcie \& Morgan scale (Krejcie \& Morgan,1970). The sample included (139) employees. The questionnaire was distributed to the sample of the study by the researchers personally and through e-mail. The number of questionnaires recovered was (125), of which (112) were valid for the statistical analysis, after excluding (13) questionnaires for incomplete.

\subsection{Sources of Data}

The study relied on data collection for two sources: Secondary data represented in documentary sources, books, articles, periodicals, university theses and publications related to the subject of the study. And preliminary data, that were collected through the questionnaire that was designed to achieve the purpose of the study in a manner commensurate with the subject of the study, its objectives and questions, and the nature of the data and information to be obtained, so that it covers all aspects that were addressed by the subject of the study. The questionnaire was distributed to workers in the upper and middle administrative levels of Jordanian telecommunications companies.

\subsection{Statistical Method of Analysis}

The SPSS program was used to analyze the study data. The statistical tools used included descriptive statistics measures, such as arithmetic averages, standard deviations, repetitions, and percentages. Internal consistency coefficient (Cronbach Alpha Coefficient) to test the stability of the study instrument. Pearson correlation coefficient for testing the presence of the phenomenon of Multicollinearity. Multiple and Stepwise Linear Regression, to test the effect of the independent variable on the dependent variable. And Hierarchical Regression analysis, to test the effect of the independent variable on the dependent variable in the presence of the moderating variable.

\subsection{Reliability Test}

The stability of the instrument used to measure the variables included in the study was tested using the Cronbach Alpha Coefficient test, where the scale result is statistically acceptable if the value of the Cronbach alpha is greater than (0.60) (Sekaran, 2013), and the closer the value from $(100 \%)$, this indicates higher degrees of stability for the study tool. According to the data presented in the Table 1, the internal consistency coefficient was measured Cronbach alpha, for the variables of the study and for their dimensions and for the study tool as a whole, find out the consistency in the answers of the members of the study sample, as follows: 
Table 1. Reliability test of study tool

\begin{tabular}{ccc}
\hline Number & Variable & $\begin{array}{c}\text { Reliability } \\
\text { Coefficient }(\alpha)\end{array}$ \\
\hline 1 & Variety & 0.864 \\
2 & Velocity & 0.615 \\
3 & Volume & 0.672 \\
4 & Veracity & 0.642 \\
& Big Data & 0.853 \\
5 & Online Analytical Processing (OLAP) & 0.640 \\
6 & Data Mining & 0.757 \\
7 & Data Warehouse & 0.858 \\
& Business Intelligence & 0.834 \\
8 & Financial Reports Quality & 0.821 \\
& All paragraphs & 0.931
\end{tabular}

We observe from Table 1 that the values of Cronbach's Alpha Coefficient for all paragraphs of the study tool (0.931), and the Cronbach's Alpha Coefficient for the paragraphs of big data, while the Cronbach's Alpha Coefficient for business intelligence paragraphs (0.834), while Cronbach's Alpha Coefficient for Financial Reports Quality Paragraphs (0.821). Consequently, all values are greater than $(0.70)$ and this is an indication of the consistency between the paragraphs of the study instrument, and the reliability of the study tool for conducting statistical analysis.

\subsection{Description of Study Sample Characteristics}

Table 2. Describing the characteristics of the demographic and personal sample

\begin{tabular}{cccc}
\hline Variable & Category & $\begin{array}{c}\text { Frequency (out of } \\
112)\end{array}$ & percentage \\
\hline \multirow{3}{*}{ Age } & Less than 35 years old & 21 & 18.7 \\
& 35 to less 45 years & 48 & 42.9 \\
& 45 to less than 55 years & 32 & 28.6 \\
55 years and over & 11 & 9.8 \\
Education & Bachelor's & 75 & 67.0 \\
& Master's & 24 & 21.4 \\
& PhD & 13 & 11.6 \\
Years of Experience & $5-10$ Y & 22 & 19.6 \\
& $11-15$ Y & 41 & 36.6 \\
& $16-20$ Y & 28 & 25.0 \\
& $>20$ & 21 & 18.8 \\
Job Title & General manager / Assistant General & 3 & 2.7 \\
& Manager & 45 & 40.2 \\
& Director of the department or unit & 64 & 57.1 \\
\hline
\end{tabular}

Table 2 indicates that the age Category (from 35 years to less than 45 years) constituted the largest percentage of respondents, which amounted to (42.9\%), followed by the age group (from 45 years to less than 55 years), which reached $(28.6 \%)$. This corresponds to the age of access to leadership and management positions, and the dependence of the telecommunications sector on those with expertise and competence in human resources as a result of the wide spread of its various activities and branches. The results in Table 2 also show that (76.0\%) of the sample individuals are holders of the first university degree (Bachelor's), and (33.0\%) of them have a higher university degree $(\mathrm{MA}, \mathrm{PhD})$, which indicates The individuals of the sample possess the knowledge and skills 
necessary to carry out administrative duties and tasks, as confirmed by the years of experience of the members of the study sample, where the experience category (from 10 years to less than 15 years) reached the largest percentage which constituted (36.6\%), and this result also confirms the ability Respondents from the study sample individuals to answer the paragraphs of the study tool objectively. As for the job title, it has been found that the percentage $(57.1 \%)$ of the sample members are from (Head of the Department), while the category (general manager / deputy general manager) formed the smallest percentage which reached $(2.7 \%)$, and this corresponds to the administrative pyramid in Modern organizations, where the number decreases as we go towards the top of the pyramid, and increases as we go towards the top of it.

\subsection{Describe of Respondents Answers}

To describe the responses of the study sample individuals on the questionnaire paragraphs, descriptive statistics tools were used, which are the arithmetic mean, standard deviations, and ranks, and the relative importance.

The following table provides a description of the opinions of the study sample individuals, the dimensions of the study tool, which include: big data (Variety, Velocity, Volume, and Veracity), business intelligence (Online Analytical Processing (OLAP), Data Mining, and Data Warehouse), and the financial reports quality. The results are as follows:

Table 3. Arithmetic averages, standard deviations, levels and relative importance of all dimensions of the study tool

\begin{tabular}{|c|c|c|c|c|c|}
\hline \multicolumn{2}{|c|}{ Item } & \multirow{2}{*}{$\begin{array}{r}\text { Mean } \\
3.841\end{array}$} & \multirow{2}{*}{$\begin{array}{c}\begin{array}{c}\text { Standard } \\
\text { Deviation }\end{array} \\
0.738\end{array}$} & \multirow{2}{*}{$\begin{array}{c}\begin{array}{c}\text { Relative } \\
\text { Importance }\end{array} \\
\text { High }\end{array}$} & \multirow{2}{*}{$\begin{array}{c}\text { Rank } \\
4\end{array}$} \\
\hline \multirow{5}{*}{$\begin{array}{l}\text { The Independent } \\
\text { Variable (Big Data) }\end{array}$} & Variety & & & & \\
\hline & Velocity & 3.979 & 0.432 & High & 2 \\
\hline & Volume & 3.887 & 0.499 & High & 3 \\
\hline & Veracity & 4.084 & 0.430 & High & 1 \\
\hline & Big Data & 3.948 & 0.396 & High & \\
\hline \multirow{4}{*}{$\begin{array}{l}\text { Moderating Variable } \\
\text { (Business Intelligence) }\end{array}$} & $\begin{array}{l}\text { Online Analytical } \\
\text { Processing (OLAP) }\end{array}$ & 3.891 & 0.471 & High & 3 \\
\hline & Data Mining & 3.958 & 0.500 & High & 2 \\
\hline & Data Warehouse & 4.061 & 0.447 & High & 1 \\
\hline & Business Intelligence & 3.970 & 0.389 & High & \\
\hline $\begin{array}{l}\text { Dependent Variable } \\
\text { (Financial Reports } \\
\text { Quality) }\end{array}$ & Financial Reports Quality & 3.962 & 0.505 & High & \\
\hline
\end{tabular}

The results in Table 3 indicate the following:

First: Big Data

Table 3 indicates that the attitudes of the sample individuals were towards the high relative importance of the dimensions of Big Data, where the mean (3.948), and a standard deviation (0.396), The dimension (Big Data Veracity) came first, with mean (4.084), and a standard deviation (0.430), while the dimension (Big Data Variety) came last, with a mean (3.841), a standard deviation (0.738), and with importance Relativity is high. All dimensions of big data appeared to be of high relative importance.

Second: Business Intelligence

Table 3 indicates that the attitudes of the sample individuals were towards the high relative importance of the dimensions of Business Intelligence, where the mean (3.970), and a standard deviation (0.389), The dimension (Data Warehouse) came first, with mean (4.061), and a standard deviation (0.447), while the dimension (Online Analytical Processing (OLAP)) came last, with a mean (3.891), a standard deviation (0.471), and with importance Relativity is high. All dimensions of Business Intelligence appeared to be of high relative importance. 
Third: Financial Reports Quality

Table 3 indicates that the attitudes of the sample individuals were towards the high relative importance of the Financial Reports Quality, where the mean (3.962), and a standard deviation (0.505).

\section{Study Hypotheses Test}

To test the study hypotheses, various statistic tests using multiple regression analysis, stepwise regression analysis, and path analysis were used, depending on the SPSS program. Before applying the analysis procedures, the data was checked for data from the phenomenon of multicollinearity, as this phenomenon indicates that there is a near-perfect linear correlation between two or more variables, which amplifies the value of the determining factor $\mathrm{R}^{2}$ and makes it greater than its actual value, the linear correlation coefficient was calculated for each variable, the results were as follows:

Table 4. Multiple correlation matrix for independent variables and moderating variable

\begin{tabular}{cccccccc}
\hline Variable & Variety & Velocity & Volume & Veracity & (OLAP) & Data Mining & Data Warehouse \\
\hline Variety & 1 & & & & & & \\
Velocity & $0.437^{* *}$ & 1 & & & & & \\
Volume & $0.389^{* *}$ & $0.323^{* *}$ & 1 & & & & \\
Veracity & $0.279^{* *}$ & 0.169 & $0.310^{* *}$ & 1 & & & \\
(OLAP) & $0.467^{* *}$ & $0.408^{* *}$ & $0.431^{* *}$ & $0.211^{*}$ & 1 & & \\
Data Mining & $0.465^{* *}$ & $0.324^{* *}$ & $0.469^{* *}$ & $0.316^{* *}$ & $0.457^{* *}$ & 1 & \\
Data Warehouse & $0.330^{* *}$ & 0.137 & $0.378^{* *}$ & $0.230^{*}$ & $.254^{* *}$ & $0.355^{* *}$ & 1
\end{tabular}

**statistically significant at the level of significance of 0.01 , *statistically significant at the level of significance of 0.05

Table 4 shows that the highest value of the correlation coefficient was found between the independent variables (Volume) and (Data Mining), which reached (0.469), while the correlation coefficient between the other variables was lower, this indicates that there is no perfect correlation between study variables. Linear correlation coefficients above (0.80) may be indicative of multicollinearity (Guajarati, 2004, 359). Therefore, it is possible to say that the study sample is free from the problem of multicollinearity.

Results of testing the first main hypothesis and its sub-hypotheses:

Table 5. Results of the first main hypothesis test $\mathrm{H} 01$

\begin{tabular}{|c|c|c|c|c|c|c|c|c|c|}
\hline \multirow{2}{*}{$\begin{array}{l}\text { Dependent } \\
\text { Variable }\end{array}$} & \multicolumn{2}{|c|}{$\begin{array}{c}\text { Model } \\
\text { Summery }\end{array}$} & \multicolumn{2}{|c|}{ ANOVA } & \multicolumn{5}{|c|}{ Coefficients } \\
\hline & $\mathrm{R}$ & $\mathrm{R}^{2}$ & $\mathrm{~F}$ & Sig F* & $\begin{array}{l}\text { Independent } \\
\text { Variables } \\
\text { (Big Data) }\end{array}$ & B & $\begin{array}{l}\text { Standard } \\
\text { error }\end{array}$ & $\begin{array}{c}\text { calculated } \\
\mathrm{T}\end{array}$ & Sig t* \\
\hline \multirow{4}{*}{$\begin{array}{l}\text { Financial Reports } \\
\text { Quality }\end{array}$} & \multirow{4}{*}{0.598} & \multirow{4}{*}{0.358} & \multirow{4}{*}{14.908} & \multirow{4}{*}{0.000} & Volume & 0.195 & 0.073 & 2.680 & 0.009 \\
\hline & & & & & Velocity & 0.100 & 0.113 & 0.883 & 0.379 \\
\hline & & & & & Variety & 0.356 & 0.098 & 3.634 & 0.000 \\
\hline & & & & & Veracity & 0.216 & 0.099 & 2.174 & 0.032 \\
\hline
\end{tabular}

*The effect is statistically significant at level $(\alpha \leq 0.05)$

It appears from the Table 5 that the correlation coefficient has reached $(\mathrm{R}=0.598)$ and it indicates the relationship between the independent variables (big data) and the dependent variable (the quality of financial reports), as it turns out that the effect of the independent variables on the dependent variable is a positive significant statistically significant effect, Where the calculated value of $F$ reached (14.908), and the level of significance $(\mathrm{Sig}=0.000)$ which is less than $(0.05)$, and it was found that the value of the determination coefficient $\left(\mathrm{R}^{2}=0.358\right)$ indicates that the variance in the big data has explained $(35.8 \%)$ of the variance In the Financial Reports Quality.

Accordingly, we reject the first null hypothesis, and accept the alternative hypothesis, which states that: There is a statistically significant effect at the significance level $(\alpha \leq 0.05)$ of the Big Data in terms of its dimensions (Variety, Velocity, Volume, Veracity) on the financial reports quality. 
This result indicates that the use of big data provides great opportunities in improving the quality of financial reports, as it enables access to a wide range of unorganized data, which could not be accessed without the use of big data technologies. This finding is consistent with (Bhimani \& Willcocks, 2014; Warren et al., 2015) who concluded that accounting is affected by big data.

Regarding the results of testing the sub-hypotheses related to the first main hypothesis, the following values were shown in the table of coefficients:

The table of coefficients showed that the value of $\mathrm{B}$ at (Volume) reached (0.195) and that the value of $\mathrm{T}$ is (2.680) with the level of significance ( $\mathrm{Sig}=0.009)$, which is less than $(0.05)$, indicating that the effect of this dimension is significant. Accordingly, we reject the first null sub-hypotheses, and accept the alternative hypothesis: "There is a statistically significant effect at the significance level $(\alpha \leq 0.05)$ of Volume on the financial reports quality".

The table of coefficients showed that the value of B at (Velocity) reached $(0.100)$ and that the value of $\mathrm{T}$ is $(0.883)$ with the level of significance ( $\mathrm{Sig}=0.379)$, which is more than 0.05 , indicating that the effect of this dimension is not significant. Accordingly, the second null sub-hypothesis has been accepted, which states that: "There is no statistically significant effect at the significance level $(\alpha \leq 0.05)$ of Velocity on the financial reports quality".

The table of coefficients showed that the value of B at (Variety) reached (0.356) and that the value of $\mathrm{T}$ is (3.634) with the level of significance ( $\mathrm{Sig}=0.000$ ), which is less than 0.05 , indicating that the effect of this dimension is significant. Accordingly, we reject the third null sub-hypotheses, and accept the alternative hypothesis: "There is a statistically significant effect at the significance level $(\alpha \leq 0.05)$ of Variety on the financial reports quality".

The table of coefficients showed that the value of B at (Veracity) reached $(0.216)$ and that the value of $\mathrm{T}$ is (2.174) with the level of significance ( $\mathrm{Sig}=0.032$ ), which is less than 0.05 , indicating that the effect of this dimension is significant. Accordingly, we reject the fourth null sub-hypotheses, and accept the alternative hypothesis: "There is a statistically significant effect at the significance level $(\alpha \leq 0.05)$ of Veracity on the financial reports quality".

To determine which of the big data dimensions had the most significant impact on the financial reports quality, a stepwise regression analysis was used, and the result was as follows:

Table 6. Results of stepwise regression analysis

\begin{tabular}{|c|c|c|c|c|c|c|c|}
\hline Model & Big Data & B & Calculated $t$ value & Sig* & $\mathrm{R}^{2}$ & $\begin{array}{c}\text { Calculated } \\
\text { F }\end{array}$ & Sig* \\
\hline First Model & Variety & 0.553 & 5.970 & 0.000 & 0.245 & 35.638 & 0.000 \\
\hline \multirow{3}{*}{ Second Model } & Variety & 0.420 & 4.395 & 0.000 & \multirow{3}{*}{0.324} & \multirow{3}{*}{26.181} & \multirow{3}{*}{0.000} \\
\hline & Volume & 0.244 & 3.588 & 0.001 & & & \\
\hline & Variety & 0.372 & 3.854 & 0.000 & & & \\
\hline \multirow[t]{2}{*}{ Third Model } & Volume & 0.217 & 3.195 & 0.002 & \multirow[t]{2}{*}{0.353} & \multirow[t]{2}{*}{19.658} & \multirow[t]{2}{*}{0.000} \\
\hline & Veracity & 0.217 & 2.189 & 0.031 & & & \\
\hline
\end{tabular}

*The effect is statistically significant at level $(\alpha \leq 0.05)$

The results of the regression analysis show the order of entry of variables in the regression model that represents the effect of the big data on financial reports quality. Where it was found that Variety ranked first, and explained (\%24.5) of the variance in the dependent variable. When (Volume) add in the second model, the explanation ratio increased to (\%32.4). The addition of (Veracity) led to a high rate of interpretation to reach (\%35.3). We note that the effect of all independent variables had a significant effect at a level of significance less than 0.05 . Except for the dimension (Velocity). 
Results of testing the second main hypothesis and its sub-hypotheses:

Table 7. Results of the second main hypothesis test $\mathrm{H} 02$

\begin{tabular}{|c|c|c|c|c|c|c|c|c|c|}
\hline \multirow[b]{2}{*}{$\begin{array}{l}\text { Dependent } \\
\text { Variable }\end{array}$} & \multicolumn{2}{|c|}{$\begin{array}{l}\text { Model } \\
\text { Summery }\end{array}$} & \multicolumn{2}{|c|}{ ANOVA } & \multicolumn{5}{|c|}{ Coefficients } \\
\hline & $\mathrm{R}$ & $\mathrm{R}^{2}$ & $\mathrm{~F}$ & Sig F* & $\begin{array}{l}\text { Moderating } \\
\text { Variable } \\
\text { (Business } \\
\text { Intelligence) }\end{array}$ & B & $\begin{array}{l}\text { Standard } \\
\text { error }\end{array}$ & $\begin{array}{c}\text { calculated } \\
\mathrm{T}\end{array}$ & Sig t* \\
\hline \multirow{3}{*}{$\begin{array}{l}\text { Financial Reports } \\
\text { Quality }\end{array}$} & \multirow{3}{*}{0.602} & \multirow{3}{*}{0.363} & \multirow{3}{*}{20.508} & \multirow{3}{*}{0.000} & (OLAP) & 0.243 & 0.111 & 2.194 & 0.030 \\
\hline & & & & & Data Mining & 0.383 & 0.101 & 3.802 & 0.000 \\
\hline & & & & & $\begin{array}{c}\text { Data } \\
\text { Warehouse }\end{array}$ & 0.310 & 0.101 & 3.069 & 0.003 \\
\hline
\end{tabular}

*The effect is statistically significant at level $(\alpha \leq 0.05)$

It appears from the Table 7 that the correlation coefficient has reached $(\mathrm{R}=0.602)$ and it indicates the relationship between the modified variable (Business intelligence) and the dependent variable (the quality of financial reports), as it turns out that the effect of the independent variables on the dependent variable is a positive significant statistically significant effect, Where the calculated value of $F$ reached (20.508), and the level of significance ( $\mathrm{Sig}=0.000)$ which is less than $(0.05)$, and it was found that the value of the determination coefficient $\left(\mathrm{R}^{2}=0.363\right)$ indicates that the variance in the Business intelligence has explained (\%36.3) of the variance In the Financial Reports Quality.

Accordingly, we reject the second null hypothesis, and accept the alternative hypothesis, which states that: There is a statistically significant effect at the significance level $(\alpha \leq 0.05)$ of Business intelligence in terms of its dimensions (Online Analytical Processing (OLAP), Data Mining, and Data Warehouse) on the financial reports quality.

Regarding the results of testing the sub-hypotheses related to the second main hypothesis, the following values were shown in the table of coefficients:

The table of coefficients showed that the value of B at (Online Analytical Processing (OLAP)) reached (0.243) and that the value of $\mathrm{T}$ is (2.194) with the level of significance ( $\mathrm{Sig}=0.030)$, which is less than (0.05), indicating that the effect of this dimension is significant. Accordingly, we reject the first null sub-hypotheses, and accept the alternative hypothesis: "There is a statistically significant effect at the significance level $(\alpha \leq 0.05)$ of Online Analytical Processing (OLAP) on the financial reports quality".

The table of coefficients showed that the value of B at (Data Mining) reached $(0.383)$ and that the value of T is (3.802) with the level of significance $(\mathrm{Sig}=0.000$ ), which is less than 0.05 , indicating that the effect of this dimension is significant. Accordingly, we reject the second null sub-hypotheses, and accept the alternative hypothesis: "There is a statistically significant effect at the significance level $(\alpha \leq 0.05)$ of Data Mining on the financial reports quality".

The table of coefficients showed that the value of B at (Data Warehouse) reached $(0.310)$ and that the value of T is (3.069) with the level of significance $(\mathrm{Sig}=0.003)$, which is less than 0.05 , indicating that the effect of this dimension is significant. Accordingly, we reject the third null sub-hypotheses, and accept the alternative hypothesis: "There is a statistically significant effect at the significance level $(\alpha \leq 0.05)$ of Data Warehouse on the financial reports quality".

The results of analyzing this hypothesis confirm that the use of business intelligence solutions has effects on data quality and quality of information and thus the quality of financial reports. This proves appropriate management calls for business intelligence (including data quality management initiatives) expressed in the relevant literature (Yeoh \& Koronios, 2010; Shollo \& Galliers, 2015), which provides evidence of the importance of appropriate management of business intelligence technologies. This leads us to the conclusion that organizations with the resources to enable superior business intelligence management will also achieve more benefits from Business Intelligence solutions in relation to financial reporting.

To determine which of the Business intelligence dimensions had the most significant impact on the financial reports quality, a stepwise regression analysis was used, and the result was as follows: 
Table 8. Results of stepwise regression analysis

\begin{tabular}{|c|c|c|c|c|c|c|c|}
\hline Model & Business intelligence & B & Calculated $t$ value & Sig* & $\mathrm{R}^{2}$ & $\begin{array}{c}\text { Calculated } \\
\text { F }\end{array}$ & Sig* \\
\hline First Model & Data Mining & 0.581 & 6.363 & 0.000 & 0.269 & 40.488 & 0.000 \\
\hline \multirow{3}{*}{ Second Model } & Data Mining & 0.472 & 5.045 & 0.000 & \multirow{3}{*}{0.335} & \multirow{3}{*}{27.396} & \multirow{3}{*}{0.000} \\
\hline & Data Warehouse & 0.335 & 3.275 & 0.001 & & & \\
\hline & Data Mining & 0.383 & 3.802 & 0.000 & & & \\
\hline \multirow[t]{2}{*}{ Third Model } & Data Warehouse & 0.310 & 3.069 & 0.003 & \multirow[t]{2}{*}{0.363} & \multirow[t]{2}{*}{20.508} & \multirow[t]{2}{*}{0.000} \\
\hline & (OLAP) & 0.243 & 2.194 & 0.030 & & & \\
\hline
\end{tabular}

*The effect is statistically significant at level $(\alpha \leq 0.05)$

The results of the regression analysis show the order of entry of variables in the regression model that represents the effect of the Business intelligence on financial reports quality. Where it was found that Data Mining ranked first, and explained (26.9\%) of the variance in the dependent variable. When (Data Warehouse) add in the second model, the explanation ratio increased to $(33.5 \%)$. The addition of (OLAP) led to a high rate of interpretation to reach (0.363). We note that the effect of all independent variables had a significant effect at a level of significance less than 0.05 .

Results of testing the third main hypothesis and its sub-hypotheses:

Table 9. Results of the third main hypothesis test H03

\begin{tabular}{|c|c|c|c|c|c|c|c|c|c|}
\hline \multirow{2}{*}{$\begin{array}{l}\text { Moderating } \\
\text { Variable }\end{array}$} & \multicolumn{2}{|c|}{$\begin{array}{c}\text { Model } \\
\text { Summery }\end{array}$} & \multicolumn{2}{|c|}{ ANOVA } & \multicolumn{5}{|c|}{ Coefficients } \\
\hline & $\mathrm{R}$ & $\mathrm{R} 2$ & $\mathrm{~F}$ & $\begin{array}{l}\mathrm{Sig} \\
\mathrm{F}^{*}\end{array}$ & $\begin{array}{c}\text { Independent } \\
\text { variables (Big } \\
\text { Data) }\end{array}$ & B & $\begin{array}{c}\text { Standard } \\
\text { error }\end{array}$ & $\begin{array}{c}\text { calculated } \\
\mathrm{T}\end{array}$ & Sig t* \\
\hline \multirow{4}{*}{$\begin{array}{l}\text { Business } \\
\text { Intelligence }\end{array}$} & \multirow{4}{*}{0.6223} & \multirow{4}{*}{0.388} & \multirow{4}{*}{16.952} & \multirow{4}{*}{0.000} & Volume & 0.116 & 0.054 & 2.145 & 0.034 \\
\hline & & & & & Velocity & 0.108 & 0.084 & 1.291 & 0.200 \\
\hline & & & & & Variety & 0.290 & 0.073 & 3.991 & 0.000 \\
\hline & & & & & Veracity & 0.203 & 0.074 & 2.750 & 0.007 \\
\hline
\end{tabular}

*The effect is statistically significant at level $(\alpha \leq 0.05)$

It appears from the Table 9 that the correlation coefficient has reached $(\mathrm{R}=0.623)$ and it indicates the relationship between the Independent variables (Big Data) and the modified variable (Business Intelligence), as it turns out that the effect of the independent variables on the dependent variable is a positive significant statistically significant effect. Where the calculated value of F reached (16.952), and the level of significance $(\mathrm{Sig}=0.000)$ which is less than $(0.05)$, and it was found that the value of the determination coefficient $\left(\mathrm{R}^{2}=\right.$ 0.388 ) indicates that the variance in the big data has explained $(38.8 \%)$ of the variance in the Business Intelligence.

Accordingly, we reject the third null hypothesis, and accept the alternative hypothesis, which states that: There is a statistically significant effect at the significance level $(\alpha \leq 0.05)$ of the Big Data in terms of its dimensions (Variety, Velocity, Volume, Veracity) on the Business Intelligence.

Regarding the results of testing the sub-hypotheses related to the third main hypothesis, the following values were shown in the table of coefficients:

The table of coefficients showed that the value of B at (Volume) reached (0.116) and that the value of T is (2.145) with the level of significance ( $\mathrm{Sig}=0.034)$, which is less than $(0.05)$, indicating that the effect of this dimension is significant. Accordingly, we reject the first null sub-hypotheses, and accept the alternative hypothesis: "There is a statistically significant effect at the significance level $(\alpha \leq 0.05)$ of Volume on the Business Intelligence ".

The table of coefficients showed that the value of $\mathrm{B}$ at (Velocity) reached $(0.108)$ and that the value of $\mathrm{T}$ is (1.291) with the level of significance ( $\mathrm{Sig}=0.200)$, which is more than 0.05 , indicating that the effect of this dimension is not significant. Accordingly, we accept the second null sub-hypotheses: "There is no statistically significant effect at the significance level $(\alpha \leq 0.05)$ of Velocity on the Business Intelligence ". 
The table of coefficients showed that the value of B at (Variety) reached (0.290) and that the value of T is (3.991) with the level of significance ( $\mathrm{Sig}=0.000$ ), which is less than 0.05 , indicating that the effect of this dimension is significant. Accordingly, we reject the third null sub-hypotheses, and accept the alternative hypothesis: "There is a statistically significant effect at the significance level $(\alpha \leq 0.05)$ of Variety on the Business Intelligence ".

The table of coefficients showed that the value of B at (Veracity) reached $(0.203)$ and that the value of $\mathrm{T}$ is (2.750) with the level of significance ( $\mathrm{Sig}=0.007)$, which is less than 0.05 , indicating that the effect of this dimension is significant. Accordingly, we reject the fourth null sub-hypotheses, and accept the alternative hypothesis: "There is a statistically significant effect at the significance level $(\alpha \leq 0.05)$ of Veracity on the Business Intelligence ".

To determine which of the Big Data dimensions had the most significant impact on the Business Intelligence, a stepwise regression analysis was used, and the result was as follows:

Table 10. Results of step wise regression analysis

\begin{tabular}{cccccccc}
\hline Model & \multirow{2}{*}{ Big Data } & B & Calculated t value & Sig* & $\mathrm{R}^{2}$ & $\begin{array}{c}\text { Calculated } \\
\text { Sig* }\end{array}$ & Sig \\
\hline \multirow{2}{*}{ First Model } & Variety & 0.442 & 6.398 & 0.000 & 0.271 & 40.934 & 0.000 \\
& Variety & 0.352 & 4.889 & 0.000 & & & \\
Second Model & Volume & 0.165 & 3.221 & 0.002 & & & \\
& Variety & 0.307 & 4.273 & 0.000 & & & \\
\multirow{5}{*}{ Third Model } & Volume & 0.140 & 2.765 & 0.007 & 0.378 & 21.913 & 0.000 \\
& Veracity & 0.204 & 2.759 & 0.007 & & & \\
\hline
\end{tabular}

*The effect is statistically significant at level $(\alpha \leq 0.05)$

The results of the regression analysis show the order of entry of variables in the regression model that represents the effect of the big data on Business Intelligence. Where it was found that Variety ranked first, and explained $(27.1 \%)$ of the variance in the dependent variable. When (Volume) add in the second model, the explanation ratio increased to $(33.5 \%)$. The addition of (Veracity) led to a high rate of interpretation to reach $(37.8 \%)$. We note that the effect of all independent variables had a significant effect at a level of significance less than 0.05 . Except for the dimension (Velocity).

Table 11. Results of the fourth main hypothesis test H01, Hierarchical regression results to show the Moderating role of business intelligence on the impact of big data on the quality of financial reports

\begin{tabular}{|c|c|c|c|c|c|c|c|}
\hline \multirow{2}{*}{$\begin{array}{c}\text { Dependent } \\
\text { Variable }\end{array}$} & \multirow{2}{*}{$\begin{array}{l}\text { Independent } \\
\text { variables }\end{array}$} & \multicolumn{3}{|c|}{$\begin{array}{l}\text { Coefficients Table (first } \\
\text { step) }\end{array}$} & \multicolumn{3}{|c|}{$\begin{array}{c}\text { Coefficients Table (second } \\
\text { step) }\end{array}$} \\
\hline & & B & $\begin{array}{c}\text { calculated } \\
\mathrm{T}\end{array}$ & Sig t* & B & $\begin{array}{c}\text { calculated } \\
\mathrm{T}\end{array}$ & Sig $\mathrm{t}^{*}$ \\
\hline \multirow{5}{*}{$\begin{array}{c}\text { Financial Reports } \\
\text { Quality }\end{array}$} & Volume & 0.195 & 2.680 & 0.009 & 0.149 & 2.094 & 0.039 \\
\hline & Velocity & 0.100 & 0.883 & 0.379 & 0.057 & 0.524 & 0.602 \\
\hline & Variety & 0.356 & 3.634 & 0.000 & 0.242 & 2.400 & 0.018 \\
\hline & Veracity & 0.216 & 2.174 & 0.032 & 0.137 & 1.382 & 0.170 \\
\hline & $\begin{array}{l}\text { Business } \\
\text { Intelligence }\end{array}$ & & & & 0.392 & 3.129 & 0.002 \\
\hline \multicolumn{2}{|c|}{$\mathrm{R}^{2}$} & \multicolumn{3}{|c|}{0.358} & \multicolumn{3}{|c|}{0.412} \\
\hline \multicolumn{2}{|c|}{$\Delta \mathrm{R}^{2}$} & \multicolumn{3}{|c|}{0.358} & \multicolumn{3}{|c|}{0.054} \\
\hline \multicolumn{2}{|c|}{$\Delta \mathrm{F}$} & \multicolumn{3}{|c|}{14.908} & \multicolumn{3}{|c|}{9.790} \\
\hline \multicolumn{2}{|c|}{$\operatorname{Sig} \Delta \mathrm{F}$} & \multicolumn{3}{|c|}{0.000} & \multicolumn{3}{|c|}{0.002} \\
\hline
\end{tabular}

*The effect is statistically significant at level $(\alpha \leq 0.05)$

The above table shows the results of a hierarchical regression based on two models, as the results of the first model based on the first step reflected a statistically significant effect of (big data) dimensions in (Financial Reports Quality), where the value of $(\Delta \mathrm{F}=14.908)$ and the level of significance (Sig $\Delta \mathrm{F}=0,000)$ which is less 
than 0.05 , as was the value of the determination coefficient $\left(\mathrm{R}^{2}=0.358\right)$, and this indicates that (big data dimensions) explain (35.8\%) of the variance in (Financial Reports Quality).

In the second step, a (business intelligence) variable was entered for the regression model, where the value of the determining factor $\mathrm{R} 2$ increased by $(0.054 \%)$, and this ratio is statistically significant as the value of $(\Delta \mathrm{F}=9.790)$ and the level of significance ( $\mathrm{Sig} \Delta \mathrm{F}=0.002)$ which is less than 0.05 , as was the value of $(\mathrm{B}=0.392)$ at (business intelligence), and at the level of significance (Sig $t=0.002)$, and this confirms the difference in the moral impact of the big data dimensions on the quality of financial reports depending on the difference in business intelligence. Accordingly, we conclude that:

Business intelligence improves the impact of big data in terms of its dimensions (Volume, Velocity, Variety, and Veracity) on the Financial Reports Quality."

The results of testing this hypothesis indicate the important effects of sound business intelligence practice regarding the quality of data and financial reports, which is consistent with the concept presented by (Duan and Xu, 2012; Loshin, 2013; Balachandran \& Prasad). Where big data management using business intelligence techniques contributes to ensuring accuracy, consistency, completeness, and transparency and thus confidence in the data and achieving high levels of information quality, the introduction of large-scale business intelligence solutions may lead to significant benefits in terms of financial reporting.

\section{Conclusions and Recommendation}

This study aimed at discovering the potential impact of big data on financial reports quality in the present business intelligence as a moderating variable. The study relied on theoretical construction on the resource-based perspective, given that the company derives its distinction in the performance of its functions, including the function of preparing the financial report from the resources and capabilities that it possesses which may be valuable, rare, and is not amenable to fully imitate. Where knowledge of what resources the big data possesses the company, and the extent to which the company uses business intelligence techniques is the key to the company's success in providing high-value information that contributes to the users of accounting data making informed decisions.

The study reached a set of results, the most prominent of which was the presence of a statistically significant effect of using big data to improve the quality of financial reports, Business intelligence contributes to improving the impact of big data in terms of its dimensions (Volume, Velocity, Variety, and Veracity) on the quality of financial reports. This result indicates business intelligence technology that is used in new technologies for the digital economy results in an increase in the security and efficiency of information use - the main resource for the digital economy, where the facts of companies' financial and economic activities can be recorded and stored more reliably, which increases the speed of processing and verifying records when the use of business intelligence technology, where business intelligence contributes to processing large amounts of data, and by monitoring the flow of accounting numbers in real time. And the big data push the preparation of accounting reports to take a special format - a continuous flow of data provided in near real time through the use of modern information technologies, which enables all stakeholders to work with this type of modern information technology. Big data technologies will allow to automatically verify an important part of the important information that constitutes financial (accounting) and non-financial reporting. This will significantly reduce the cost and time required to prepare financial reports. This finding is consistent with the findings of Sun et al. (2018), who indicated that big data analyzes provide the ability to capture causal and interrelated processes on a real-time basis. Likewise, what Warren et al. (2015) have indicated, who assert that big data can significantly affect the future of financial reporting and the evolution of generally accepted accounting principles specifically for reporting off-balance-sheet assets and fair value calculations.

The volumes of big data have had no impact on the quality of the financial reports. This may be due to the fact that the increased amounts of data collected due to their speed and the diversity of their available resources, companies do not need to have all of them as long as they can access them, and therefore the large flow of data may hinder the authors of financial reports, and therefore have no effect in improving the quality of financial reports. It is difficult for companies to deal with huge amounts of data.

Finally, this study recommends the necessity of working on making use of big data and resorting to business intelligence solutions because of its great role in improving the quality of financial reports and thus supporting decision-making functions for a large group of users. 


\section{References}

Abbasi A, Sarker S, Chiang RH. (2016). Big data research in information systems: toward an inclusive research agenda. J Assoc Inf Syst, 17(2), 1-32. https://doi.org/10.17705/1jais.00423

Alles, M. (2015). Drivers of the Use and Facilitators and Obstacles of the Evolution of Big Data by the Audit Profession. Accounting Horizons, 29(2), 439-449. https://doi.org/10.2308/acch-51067

Aslanertik B.E., \& Yardımc1 B. (2019). A Comprehensive Framework for Accounting 4.0: Implications of Industry 4.0 in Digital Era. In: Hacioglu U. (eds) Blockchain Economics and Financial Market Innovation. Contributions to Economics. Springer, Cham. https://doi.org/10.1007/978-3-030-25275-5_27

Balachandran, B., \& Prasad, S. (2017). Challenges and benefits of deploying big data analytics in the cloud for business intelligence. Procedia Comput. Sci, 112, 1112-1122. https://doi.org/10.1016/j.procs.2017.08.138

Bhimani, A., \& Willcocks, L.P. (2014). Digitisation, 'big data' and the transformation of accounting information. Accounting and Business Research, 44(4), 469-490. https://doi.org/10.1080/00014788.2014.910051

Bhimani, A., \& Willcocks, L. (2014). Digitisation, 'big data' and the transformation of accounting information. Accounting and Business Research, 44(4), 469-490. https://doi.org/10.1080/00014788.2014.910051

Chauke, T.A. (2018). Integration of information management systems to enhance business intelligence at the department of transport in South Africa, MINF Dissertation, University of South Africa, Pretoria

Chen, H., Chiang, R., \& Storey, V. (2012). Business intelligence and analytics: from big data to big impact. MIS Quarterly, 36(4), 1165-1188. https://doi.org/10.2307/41703503

Davenport, T. H. (2014). Big data at work: dispelling the myths, uncovering the opportunities. Harvard Business School Press. Boston.

Davis, C. K. (2014). Beyond data and analysis. Communications of the ACM, 57(6), 39-41. https://doi.org/10.1145/2602326

De Mauro, A., Greco, M., \& Grimaldi, M. (2015). What is big data? A consensual definition and a review of key research topics. AIP Conference Proceedings, 10, 97-104. https://doi.org/10.1063/1.4907823

Duan L., \& Xu L.D. (2012). Business intelligence for enterprise systems: a survey. Industrial Informatics, IEEE Transactions, 8(c), 1-9. https://doi.org/10.1109/TII.2012.2188804

George S., Anna S., \& Stuart T. (2019). Big Data and changes in audit technology: contemplating a research agenda. Accounting and Business Research, 49(1), 95-119. https://doi.org/10.1080/00014788.2018.1459458

Griffin, P. A., \& Wright, A. M. (2015). Commentaries on Big Data's importance for accounting and auditing. Accounting Horizons, 29(2), 377- 379. https://doi.org/10.2308/acch-51066

Guajarati, D.N. (2004). Basic Econometrics. (4 ${ }^{\text {th }}$ ed.), USA: New York: McGraw Hill.

Kamordzhanova N., \& Selezneva A. (2019). The Impact of the Digital Economy on Accounting, Reporting and Audit, Advances in Economics. Business and Management Research, 79, 228-230.http://creativecommons.org/licenses/by-nc/4.0/

Krejcie, R.V., \& Morgan D. W. (1970). Determining Sample Size for Research Activities. Educational and Psychological Measurement, 30, 607-610. https://doi.org/10.1177/001316447003000308

Kumar, C. S., \& Dhinesh Babu, L. D. (2018). Review on Big Data and Its Impact on Business Intelligence. Information Systems Design and Intelligent Applications, 93-109. https://doi.org/10.1007/978-981-13-3329-3_10

Loshin D. (2013). Business Intelligence. The Savvey Managers Guide, Elsevier Morgan Kaufmann publisher, USA.

McAfee A, Brynjolfsson E, Davenport TH, Patil DJ, \& Barton D. (2012). Big data: the Manag revolution. Harv Bus Rev, 90(10), 61-67.

Popovic A. \& Yeoh W. (2016). Extending the Understanding of Critical Success Factors for Implementing Business Intelligence Systems. Journal of the Association for Information Science and Technology, 67(1), 134-147. https://doi.org/10.1002/asi.23366

Ramesh, B. (2015). Big data architecture. Big Data, 29-59, New Delhi: Springer. https://doi.org/10.1007/978-81-322-2494-5_2

Rouhani, S., Ashrafi, A., Ravasan, A., \& Afshari, S. (2016). The impact model of business intelligence on 
decision support and organizational benefits. Journal of Enterprise Information Management, 29(1), 19-50. https://doi.org/10.1108/JEIM-12-2014-0126

Sangari, M. S., \& Razmi, J. (2015). Business intelligence competence, agile capabilities, and agile performance in supply chain. The International Journal of Logistics Management, 26(2), 356-380. https://doi.org/10.1108/IJLM-01-2013-0012

Sekaran, U. (2013). Research methods for business (6 ${ }^{\text {th }}$ ed.). Hoboken, NJ: John Wiley \& Sons.

Shollo, A., \& Galliers, R. D. (2015). Towards an understanding of the role of business intelligence systems in organisational knowing. Information Systems Journal, 26(4), 339-367. https://doi.org/10.1111/isj.12071

Sun, Z., Sun, L., \& Strang, K. (2018). Big Data analytics services for enhancing business intelligence. Journal Of Computer Information Systems, 58(2). https://doi.org/10.1080/08874417.2016.1220239

Vasarhelyi, M. A., Kogan, A., \& Tuttle, B. M. (2015). Big Data in Accounting: An Overview. Accounting Horizons, 29(2), 381- 396. https://doi.org/10.2308/acch-51071

Varma, A. (2018). Big Data Usage Intention of Management Accountants: Blending the Utility Theory with the Theory of Planned Behavior in an Emerging Market Context. Theoretical Economics Letters, 8, 2803-2817. https://doi.org/10.4236/tel.2018.813176

Warren, J. D., Moffitt, K. C., \& Byrnes, P. (2015). How Big Data will change accounting. Accounting Horizons, 29(2), 397-407. https://doi.org/10.2308/acch-51069

Warren, J., Moffitt, K., \& Byrnes, P. (2015). How big data will change accounting. Accounting Horizons, 29(2), 397-407. https://doi.org/10.2308/acch-51069

Watson, H J. (2014). Tutorial: Big Data Analytics: Concepts, Technologies, and Applications. Communications of the Association for Information Systems, 34(65). Available at: http://aisel.aisnet.org/cais/vol34/iss1/65. https://doi.org/10.17705/1CAIS.03465

Wisna, n. (2013). The Effect of Information Technology on the Quality of Accounting Information system and Its impact on the Quality of Accounting Information. Research Journal of Finance and Accounting, 4(15), 69-75.

Yeoh, William., \& Koronios, Andy. (2010). Critical success factors for business intelligence systems. Journal of computer information systems, 50(3), 23-32.

Zadeh, M., Karkon, A., \& Golnari, H. (2015). The Effect of Information Technology on the Quality of Accounting Information. Shiraz Journal of System Management, 3(3), 61-76.

\section{Copyrights}

Copyright for this article is retained by the author(s), with first publication rights granted to the journal.

This is an open-access article distributed under the terms and conditions of the Creative Commons Attribution license (http://creativecommons.org/licenses/by/3.0/). 